\title{
International Journal of Education and Management Engineering
}

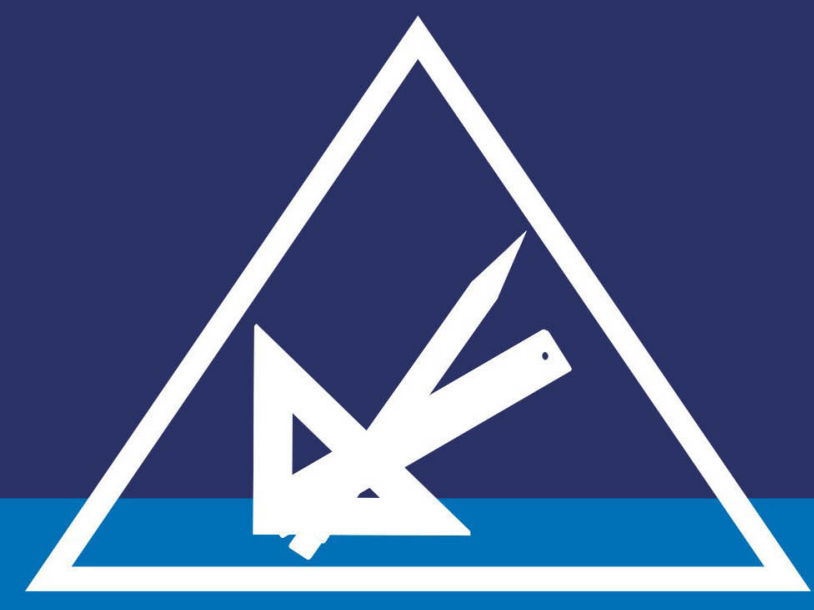

IJEME KoI.2

Http:// www.mecs-press .org Vol. 2 No.3 March 2012 


\section{International Journal of Education and Management Engineering (IJEME)}

Volume 2, Number 3, March 2012

\section{Contents}

Reflection on Project Driven LTO Teaching Method

Hua Wang, Zhijun Zheng

An efficient Group Key Management Scheme for Ad Hoc Networks

Wenqi $Y u$

Corpus-based Study on Cultural Values in EFL Coursebooks from the Perspective of Social Roles

Qiuhong $\mathrm{Hu}$

Vocal Emotion Recognition Based on HMM and GMM for Mandarin Speech

Sun Menghan, Jiang Baochen, Yuan Jing

Study on the Transform and Upgrade Strategy of Chinese Textile Processing Enterprises

Zhou Haiyan

Exploration and Practice for Evaluation of Teaching Methods

Xiaodong Wang, Yingjie $\mathrm{Wu}$

Exploration and Practice of Graduation Design for Civil Engineering

MA Zhe, HAO Xiao

Exploration and Practice of SE-CDIO Educational Pattern

Liu Jian-Bin, Yang Zhi-Yun

Study on the Scientific Research Group Management of Chinese High Technology Enterprises 57 from the Perspective of Knowledge Transfer

Wan Ting

Wind Power Generation Plant Addressing Which Based on WASP Software

Yujun Bao, Yiming He

The Graduate Education of Business Administration: The Experience From Some Developed 71 Countries

Li Liu, Junwu Chai

Dangerous Degree Evaluation of Mine Debris Flow Based on the Immune Genetic Neural 78 Network

Xicheng Xue, Jisong Bi, Lingling Chen 